\title{
Biochemical responses to a non-standard exercise in horses trained for jumping
}

\author{
Vladimír Hura $^{1}$, Franišek Novotný ${ }^{1}$, Martin Boldižár ${ }^{1}$, Martin Rédl ${ }^{1}$, Jana Noskovičová1, \\ Slavomír Horňák ${ }^{2}$, Vladimír Petrovič3 ${ }^{3}$, Gabriel Lazar ${ }^{3}$ and Gabriel Kováč ${ }^{3}$ \\ University of Veterinary Medicine and Pharmacy, ${ }^{1}$ Clinic of Horses, ${ }^{2}$ Clinic of Small Animals, \\ ${ }^{3}$ Clinic of Ruminants, Košice, Slovak Republic
}

Received June 12, 2012

Accepted March 19, 2013

\begin{abstract}
The aims of this study were to analyze the indices of mineral, enzymatic, protein and lipid metabolism, and the antioxidant status in horses trained for jumping after prolonged exercise. A total of 10 Slovak warmblood horses (aged 6-15 years) trained for jumping were used. Blood samples were taken before and after the jumping training (control), immediately after prolonged exercise and after the following $36 \mathrm{~h}$ of rest. Control samplings showed no signs of exerciseinduced dehydration, but an increase of haematological indices, increased concentration of lactate and increased activity of lactate dehydrogenase whose changes may be indicative of splenic blood efflux and activation of anaerobic metabolism. On the other hand, changes of biochemical indices (such as: increased alanine aminotrasferase, lactate dehydrogenase and creatine phosphokinase, decreased $\mathrm{K}$ and $\mathrm{Fe}$, increased malondialdehyde and glutathione peroxidase) that are indicative for the muscle membrane leakage, oxidative stress and electrolyte imbalances, and alterations of intermediary metabolism were found due to the non-standard prolonged exercise. Although this study demonstrates that trained horses adapted to a certain exercise regimen are exposed to oxidative and metabolic stress by non-standard prolonged workload, further research is required to assign an appropriate resting regime needed to compensate for the induced biochemical changes.
\end{abstract}

Equine, metabolic indices, antioxidants, performance

As published by Robert et al. (2010), studies on endurance and prolonged exercising horses often report only descriptive results, and physiological explanation of changes responsible for the observed alterations is rarely provided. It is probably due to the alterations of plasma volume which vary in horses subjected to the different physical performance on a variety of environmental conditions, as reviewed by Carlson (1987). Hypovolaemia caused by exercise-induced dehydration is a problem to which mostly endurance and prolonged exercising horses must respond.

It is well known that during prolonged exercise in horses, loss of water and electrolyte via sweat may develop exhaustion with hypovolaemia and electrolyte changes, which subsequently result in fatigue, metabolic disturbances, fractures and even death. For example, positive correlation between exercise intensity and gastric ulceration severity was proven by Bezdekova et al. (2005). Physiologically speaking, correct interpretation of the metabolic changes after prolonged or endurance exercise in horses is required, because it can help the veterinarian, trainer, or owner to choose appropriate training and post-exercise recovery as well as adequate dietary supplementation.

The aim of this study was to determine the influence of a non-standard prolonged exercise in horses trained for jumping on chosen haematological and biochemical indices which are related to mineral, enzymatic, protein and lipid metabolism and to the antioxidant status.

\section{Material and Methods}

Animals

Ten clinically healthy Slovak warmblood horses (1 stallion, 3 mares and 6 geldings), aged 6-15 years and weighing 510-670 kg (mean $590 \mathrm{~kg}$ ) were included into this study. Horses were individually housed in boxes on straw and they had free access to water and feed. Every morning at 7:00 h, all horses were fed with individually 
adjusted rations receiving the same basal diet (BD). The BD composition was: $700 \mathrm{~g}$ of hay, $200 \mathrm{~g}$ of oats and $100 \mathrm{~g}$ of granules for horse (approval number SK 100576) per $1 \mathrm{~kg}$ of DM.

The experiment was carried out in accordance with established standards for animal care and use. The protocol (no. 13/2012/EK) was approved by the Ethics Committee of the University of Veterinary Medicine and Pharmacy in Košice, Slovak Republic, and performed at the Clinic of Horses, University of Veterinary Medicine and Pharmacy in Košice, Slovak Republic.

\section{Exercise protocol}

Each of the horses in this study had been in a regular jumping training program that was made by their trainers. One week prior to exercise, the daily jumping training regime (DJTR) for each horse was based on 15 min warmup (consisting of walk $5 \mathrm{~min}$, trot $5 \mathrm{~min}$ and canter $5 \mathrm{~min}$ ) and jumping exercise for $1 \mathrm{~h}$ (fences 110 to $130 \mathrm{~cm}$ in height).

The exercise trial started at 15:00 h, preceded by $1 \mathrm{~h}$ warm-up, which the horses absolved by a walk on tarmac road. During the entire prolonged exercise, the leading horse set the pace for all horses, thus imitating the regular warm-up exercise conditions. Non-standard prolonged exercise (NPE) was used as follows: interval of performance for $15 \mathrm{~min}$ (walk about $7 \mathrm{~km} / \mathrm{h}$ for $5 \mathrm{~min}$, trot about $13 \mathrm{~km} / \mathrm{h}$ for $5 \mathrm{~min}$, and canter about $25 \mathrm{~km} / \mathrm{h}$ for $5 \mathrm{~min}$ ) was repeated for $2 \mathrm{~h}$ (phase I); rest in a outdoor paddock without access to water for 30 min (phase II); interval of performance for $15 \mathrm{~min}$ (walk $5 \mathrm{~min}$, trot $5 \mathrm{~min}$ and canter $5 \mathrm{~min}$ ) was repeated for $1 \mathrm{~h}$, but the last minute of exercise finished the horses at full-speed gallop (phase III). Routes chosen for our test consisted mainly of field roads with a moderate changes in altitude. Environmental conditions during our experiment ranged from 15 to $19^{\circ} \mathrm{C}$, with $62-88 \%$ relative atmospheric humidity.

Electrolite disturbances are a potential reason for poor performance and fatigue during exercise. As mentioned before, hypovolaemia caused by exercise-induced dehydration is a problem to which mostly endurance and prolonged exercising horses must respond. We decided to use such model of exercise where the horses were able to replenish electrolites and water loss from their internal body resources by compensatory mechanisms only.

During the $36 \mathrm{~h}$ of recovery after NPE, all horses were resting in stalls but had free access to the outdoor paddock for $12 \mathrm{~h}(8: 00-20: 00 \mathrm{~h})$ and water. On the $2^{\text {nd }}$ day after NPE, blood was taken before feeding.

\section{Sample analysis}

On the $7^{\text {th }}$ day, before (Pre) and immediately after DJTR (Post), as well as immediately after NPE (End) and after the following $36 \mathrm{~h}$ of rest $(36 \mathrm{~h})$, blood was taken to find control and experimental values of biochemical indices. Blood was collected into heparinized test tubes and test tubes with serum separator via v. jugularis puncture. Blood samples were centrifuged for plasma specimens at $1180 \mathrm{~g}$ for $15 \mathrm{~min}$. Blood in test tubes with serum separator were left at $37^{\circ} \mathrm{C}$ for $1 \mathrm{~h}$ to allow it to clot, and then centrifuged at $1180 \mathrm{~g}$ for $15 \mathrm{~min}$ and subsequently, serum was separated. All samples of blood, serum and plasma were frozen and stored at $-24^{\circ} \mathrm{C}$ until analyzed.

The standard kits from Randox (UK) were used to determine the activity of aspartate aminotransferase (AST, EC 2.6.1.1), alanine aminotransferase (ALT, EC 2.6.1.2), alkaline phosphatase (ALP, EC 3.1.3.1), $\gamma$-glutamyltransferase $(\gamma \mathrm{GT}$, EC 2.3.2.2), lactate dehydrogenase (LDH, EC 1.1.1.27), creatine phosphokinase (CPK, EC 2.7.3.2), and the concentration of creatinine (CREAT), urea (U), total cholesterol (TCH), bilirubine (BIL), triglycerides (TG), glucose (G), lactate (LACT), $\beta$-hydroxybutyrate (BHB), phosphorus (P), total proteins (TP), albumin (ALB) and total lipids (TL) in blood serum by spectrometer Alizé (Lisabio, France). The indices of blood picture were assessed using the animal blood counter (ABC VET 16p, Trigon s.r.o., Slovak Republic) and total immunoglobulins in serum by Spekol 211 (Carl-Zeiss Jena, Germany). Concentration of Na, K, Ca, Mg, $\mathrm{Cu}, \mathrm{Fe}$ and $\mathrm{Zn}$ in serum was analyzed by flame atomic absorption spectroscopy (AAnalyst 100, Perkin-Elmer, The Slovak Republic). Blood serum selenium concentration was measured using the modified AAS method described by Bax et al. (1986). Activity of blood glutathione peroxidase (GSHPx, EC 1.11.1.9) was determined using the Ransel kit (Randox). Concentration of malondialdehyde (MDA) in plasma was measured with the modified fluorimetric method according to Jo and Ahn (1998). After the sampling, red blood cell haemolysates were prepared for the analysis of the activity of superoxide dismutase (SOD, EC 1.15.1.1) and these were immediately assessed using kits from Randox. Ellman's method (1958) was used to determine the concentration of sulphydryl groups (HS-) in plasma. Concentrations of vitamins A and E were assessed using high performance liquid chromatography according to Tuckova and Kastel (1999).

Statistical procedure

The results are presented as mean \pm SEM. Statistical analysis of all results was done using paired Student's $t$-test $(P<0.05, P<0.01, P<0.001)$.

\section{Results}

After one week of DJTR, the Post-training values compared to the Pre-training values presented in units per litre were found as follows: increased concentration of $\mathrm{Hb}, \mathrm{MCV}$, $\mathrm{MCH}, \mathrm{MCHC}$, lactate and tendency to increase of activity of LDH but unchanged Hct, Ec, 
Table 1. Biochemical indices in warmblood horses assessed before (Pre) and at the end (Post) of jumping exercise on the $7^{\text {th }}$ day of the daily training regimen.

\begin{tabular}{|c|c|c|}
\hline Indices & Pre & Post \\
\hline Haematocrit $\left(1 \cdot 1^{-1}\right)$ & $0.4 \pm 0.01$ & $0.41 \pm 0.01$ \\
\hline Erythrocytes $\left(\mathrm{T} \cdot \mathrm{l}^{-1}\right)$ & $8.29 \pm 0.39$ & $8.44 \pm 0.32$ \\
\hline Haemoglobin $\left(\mathrm{g} \cdot \mathrm{dl}^{-1}\right)$ & $13.12 \pm 0.47$ & $14.48 \pm 0.54^{b}$ \\
\hline $\operatorname{MCV}\left(f \cdot l^{-1}\right)$ & $47.9 \pm 1.12$ & $48.2 \pm 1.24^{\mathrm{c}}$ \\
\hline $\mathrm{MCH}\left(\mathrm{f} \cdot \mathrm{mol}^{-1}\right)$ & $15.88 \pm 0.32$ & $17.04 \pm 0.36^{\mathrm{a}}$ \\
\hline $\left.\mathrm{MCHC} \mathrm{mmol} \cdot 1^{-1}\right)$ & $33.18 \pm 0.09$ & $35.32 \pm 0.19^{\mathrm{a}}$ \\
\hline Leukocytes $\left(\mathrm{G} \cdot \mathrm{l}^{-1}\right)$ & $6.94 \pm 0.42$ & $7.2 \pm 0.45$ \\
\hline Lactate $\left(\mathrm{mmol} \cdot \mathrm{l}^{-1}\right)$ & $0.77 \pm 0.06$ & $0.91 \pm 0.04^{b}$ \\
\hline Glucose $\left(\mathrm{mmol} \cdot \mathrm{l}^{-1}\right)$ & $6.19 \pm 0.13$ & $6.16 \pm 0.14$ \\
\hline Total cholesterol $\left(\mathrm{mmol} \cdot \mathrm{l}^{-1}\right)$ & $2.11 \pm 0.08$ & $2.02 \pm 0.08$ \\
\hline$\beta$-hydroxybutyrate $\left(\mathrm{mmol}^{-1} \mathrm{l}^{-1}\right)$ & $0.17 \pm 0.03$ & $0.19 \pm 0.02$ \\
\hline Triglycerides $\left(\mathrm{mmol} \cdot \mathrm{l}^{-1}\right)$ & $0.25 \pm 0.02$ & $0.25 \pm 0.03$ \\
\hline Total lipids $\left(\mathrm{g} \cdot \mathrm{l}^{-1}\right)$ & $3.07 \pm 0.17$ & $2.81 \pm 0.14$ \\
\hline Total protein $\left(\mathrm{g} \cdot \mathrm{l}^{-1}\right)$ & $67.0 \pm 2.14$ & $68.16 \pm 1.57$ \\
\hline Albumin $\left(g \cdot l^{-1}\right)$ & $38.9 \pm 0.98$ & $39.58 \pm 1.13$ \\
\hline Bilirubine $\left(\mu \mathrm{mol} \cdot 1^{-1}\right)$ & $31.42 \pm 5.93$ & $30.5 \pm 5.39$ \\
\hline Creatinine $\left(\mu \mathrm{mol} \cdot \mathrm{l}^{-1}\right)$ & $96.16 \pm 5.21$ & $99.86 \pm 3.87$ \\
\hline Urea $\left(\mathrm{mmol} \cdot \cdot^{-1}\right)$ & $5.57 \pm 0.39$ & $5.2 \pm 0.15$ \\
\hline Phosphorus $\left(\mathrm{mmol} \cdot \mathrm{l}^{-1}\right)$ & $1.06 \pm 0.02$ & $1.06 \pm 0.06$ \\
\hline Chloride $\left(\mathrm{mmol} \cdot 1^{-1}\right)$ & $101.1 \pm 1.2$ & $100.5 \pm 0.8$ \\
\hline $\operatorname{AST}\left(U \cdot 1^{-1}\right)$ & $302.6 \pm 13.4$ & $318.2 \pm 14.3$ \\
\hline $\operatorname{ALT}\left(U \cdot 1^{-1}\right)$ & $13.44 \pm 1.03$ & $13.56 \pm 1.03$ \\
\hline $\operatorname{ALP}\left(U \cdot 1^{-1}\right)$ & $213.4 \pm 6.8$ & $222.9 \pm 7.4$ \\
\hline$\gamma \mathrm{GT}\left(\mathrm{U} \cdot \mathrm{l}^{-1}\right)$ & $11.16 \pm 0.49$ & $11.76 \pm 0.52$ \\
\hline $\mathrm{LDH}\left(\mathrm{U} \cdot \mathrm{l}^{-1}\right)$ & $559.7 \pm 37.5$ & $594.2 \pm 56.5^{d}$ \\
\hline C CPK $\left(\mathrm{U} \cdot 1^{-1}\right)$ & $207.1 \pm 15.5$ & $198.5 \pm 6.8$ \\
\hline
\end{tabular}

Mean corpuscular volume (MCV), mean corpuscular haemoglobin $(\mathrm{MCH})$, mean corpuscular haemoglobin concentration (MCHC), aspartate aminotransferase (AST), alanine aminotransferase (ALT), alkaline phosphatase (ALP), $\gamma$-glutamyltransferase $(\gamma \mathrm{GT})$, lactate dehydrogenase $(\mathrm{LDH})$, creatine phosphokinase $(\mathrm{CPK})$

Results are presented as mean $\pm \operatorname{SEM}(\mathrm{n}=5) ;{ }^{\mathrm{a}} P<0.001 ;{ }^{\mathrm{b}} P<0.05$; ${ }^{\mathrm{c}} P \leq 0.07 ;{ }^{\mathrm{d}} P \leq 0.14$ leukocytes, unchanged concentration of GLUC, TCH, BHB, TG, TL, TP, ALB, BIL, CREAT, U, P, chloride, and unchanged activity of AST, ALT, ALP, $\gamma$ GT and CPK (Table 1).

In case of TP, ALB and TL expressed in $\mathrm{g} \cdot \mathrm{l}^{-1}$, a pattern of increase was determined due to NPE as compared End

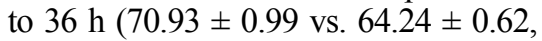
$P<0.001,43.60 \pm 1.09$ vs. $38.88 \pm 0.71$, $P<0.01$ and $3.63 \pm 0.2$ vs. $2.64 \pm 0.12$, $P<0.01$, respectively), but when ALB was calculated by $\mathrm{g}^{-\mathrm{g}^{-1}}$ of TP, no significant difference was revealed $(0.62 \pm 0.02$ vs. $0.61 \pm 0.01, P>0.05)$. Comparing the amount of TP at End to $36 \mathrm{~h}$, a difference of $6.69 \mathrm{~g} \cdot \mathrm{l}^{-1}$ (increase of 10.4 percent of value at $36 \mathrm{~h}$ ) was found.

Between End and 36h, in the case of mineral and enzymatic indices expressed in units per liter vs. units per $g$ of TP, significant changes were found in concentrations of sodium, magnesium, phosphorus, copper, and the activities of aspartate aminotransferase, alanine aminotransferase, alkaline phosphatase, $\quad \gamma$-glutamyltransferase, lactate dehydrogenase and superoxide dismutase (Table 2).

In the case of blood antioxidants, protein and lipid metabolism indices expressed in units per litre vs. units per $\mathrm{g}$ of TP (except for total cholesterol and retinol expressed as units per g of TL), significant changes were found in the concentrations of malondialdehyde, creatinine, urea, albumine, sulphydryl groups, retinol and total cholesterol at End as compared to $36 \mathrm{~h}$ (Table 3 ).

\section{Discussion}

A limitation of this study is that the level of dehydration after NPE was not determined directly by Hct and body weight loss. It is well known that the exercise-induced catecholamine-mediated release of blood from the splenic reservoir largely is attributed to the compensatory mechanisms involved in response to exercise (Carlson 1987). The increased concentration of haemoglobin, mean corpuscular volume, mean corpuscular haemoglobin and mean corpuscular haemoglobin concentration but unchanged haematocrit were found in our horses undergoing DJTR. It can be argued that dehydration did not occur in these horses after the jumping training due to the previously mentioned phenomenon. On 
Table 2. Blood mineral and enzymatic indices in warmblood horses trained for jumping determined at the end of a nonstandard prolonged exercise (End) and after the following 36 hours of a rest $(36 \mathrm{~h})$.

\begin{tabular}{lcccc}
\hline Indices & End & $36 \mathrm{~h}$ & End & $36 \mathrm{~h}$ \\
\hline $\mathrm{Na}$ & $\mathrm{mmol} \cdot \mathrm{l}^{-1}$ & & $\mathrm{mg} \cdot \mathrm{g}^{-1}$ of TP & \\
$\mathrm{K}$ & $141.9 \pm 1.2$ & $133.3 \pm 1.6^{\mathrm{b}}$ & $45.94 \pm 0.65$ & $83.78 \pm 1.04^{\mathrm{a}}$ \\
$\mathrm{Mg}$ & $2.53 \pm 0.11$ & $2.9 \pm 0.1^{\mathrm{c}}$ & $1.38 \pm 0.08$ & $1.79 \pm 0.07^{\mathrm{b}}$ \\
$\mathrm{Ca}$ & $0.81 \pm 0.04$ & $0.74 \pm 0.03$ & $0.27 \pm 0.01$ & $0.46 \pm 0.02^{\mathrm{a}}$ \\
Phosphorus & $3.63 \pm 0.13$ & $3.35 \pm 0.08$ & $2.05 \pm 0.08$ & $2.07 \pm 0.06$ \\
& $0.74 \pm 0.05$ & $0.99 \pm 0.05^{\mathrm{c}}$ & $0.43 \pm 0.02$ & $0.36 \pm 0.02^{\mathrm{c}}$ \\
$\mathrm{Cu}$ & $\mu \mathrm{mol} \cdot \mathrm{l}^{-1}$ & & $\mu \mathrm{g} \cdot \mathrm{g}^{-1}$ of TP & $12.28 \pm 0.54$ \\
$\mathrm{Zn}$ & $14.72 \pm 0.49$ & $12.9 \pm 0.7^{\mathrm{c}}$ & $13.25 \pm 0.49$ & $20.81 \pm 1.64$ \\
$\mathrm{Fe}$ & $21.95 \pm 1.71$ & $20.1 \pm 1.2$ & $20.75 \pm 1.64$ & $26.03 \pm 1.27^{\mathrm{b}}$ \\
$\mathrm{Se}$ & $26.53 \pm 1.11$ & $29.9 \pm 0.9^{\mathrm{c}}$ & $20.98 \pm 0.88$ & $1.34 \pm 0.13$ \\
& $1.09 \pm 0.12$ & $1.21 \pm 0.13$ & $1.32 \pm 0.15$ & $6.11 \pm 0.46$ \\
$\mathrm{AST}$ & $\mathrm{U} \cdot \mathrm{l}^{-1}$ & & $\mathrm{mU} \cdot \mathrm{mg}^{-1}$ of TP & $0.29 \pm 0.04^{\mathrm{f}}$ \\
$\mathrm{ALT}$ & $415.7 \pm 30.4$ & $383.0 \pm 27.7^{\mathrm{b}}$ & $0.37 \pm 0.04$ & $4.01 \pm 0.43$ \\
$\mathrm{ALP}$ & $25.4 \pm 2.8$ & $18.4 \pm 2.1^{\mathrm{e}}$ & $4.09 \pm 0.42$ & $0.24 \pm 0.03$ \\
$\gamma \mathrm{GT}$ & $289.4 \pm 24.6$ & $257.7 \pm 24.1^{\mathrm{a}}$ & $0.24 \pm 0.02$ & $9.41 \pm 0.79^{\mathrm{d}}$ \\
LDH & $22.9 \pm 6.0$ & $20.3 \pm 5.1^{\mathrm{e}}$ & $11.17 \pm 1.28$ & $3.35 \pm 0.42^{\mathrm{c}}$ \\
$\mathrm{CPK}$ & $803.3 \pm 77.8$ & $621.1 \pm 50.0^{\mathrm{b}}$ & $6.23 \pm 0.80$ & \\
\hline
\end{tabular}

Total protein (TP), aspartate aminotransferase (AST), alanine aminotransferase (ALT), alkaline phosphatase (ALP), $\gamma$-glutamyltransferase (GGT), lactate dehydrogenase (LDH), creatine phosphokinase (CPK).

Results are presented as mean $\pm \operatorname{SEM}(\mathrm{n}=10) ;{ }^{\mathrm{a}} P<0.001 ;{ }^{\mathrm{b}} P<0.01 ;{ }^{\mathrm{c}} P<0.05 ;{ }^{\mathrm{d}} P \leq 0.06 ;{ }^{\mathrm{e}} P \leq 0.08 ;{ }^{\mathrm{f}} P \leq 0.16$

the other hand, during the entire NPE the horses had no access to water, thus some degree of dehydration might have been occurred. Snow et al. (1982), and Rose and Hodgson (1994) stated that the concentration of TP and ALB can provide the degree of dehydration in horses after exercise. Similar increase of TP ( 9 percent of rest value) after an exercise was observed by Zobba et al. (1982), but the authors support the opinion of McKeever et al. (1993) that the reason for mild haemoconcentration could be the intercompartmental fluid shift rather than dehydration caused by sweating.

Nevertheless, in contrast to DJTR, the amounts of total protein, albumin and total lipids were increased after NPE. For that reason, all studied indices in response to the NPE, which are presented in this study were calculated by units per $g$ of TP (or units per $g$ of TL) along with units per litre. We can presume that the blood indices counted in units per $\mathrm{g}$ of TP can reflect more accurately the observed biochemical changes because the impact of prolonged exercise induced dehydration is included in their interpretation, which is not the case of the results presented in units per litre. Furthermore, we avoided comparing our findings with studies performed on humans and animal species other than horses because it is well known that different compensation mechanisms with regard to the exercise-induced dehydration are involved.

\section{Mineral metabolism}

Comparing units per litre to units per $\mathrm{g}$ of TP, the opposite changes were found in the concentration of $\mathrm{Na}, \mathrm{Mg}, \mathrm{P}$ due to the NPE. As published by Flaminio and Bonnie (1998), concentrations of $\mathrm{Na}, \mathrm{K}$ and $\mathrm{Mg}$ are high but the amount of calcium is low in sweat, which could cause the observed changes in these indices when expressed as units 
Table 3. Blood antioxidants, protein and lipid metabolism indices in warmblood horses trained for jumping determined at the end of a non-standard prolonged exercise (End) and after the following $36 \mathrm{~h}$ of rest ( $36 \mathrm{~h}$ ).

\begin{tabular}{|c|c|c|c|c|}
\hline Indices & End & $36 \mathrm{~h}$ & End & $36 \mathrm{~h}$ \\
\hline & $\mu \mathrm{mol} \cdot \mathrm{l}^{-1}$ & & $\mu \mathrm{g} \cdot \mathrm{g}^{-1}$ of TP & \\
\hline MDA & $0.37 \pm 0.02$ & $0.32 \pm 0.01^{\mathrm{a}}$ & $0.38 \pm 0.01$ & $0.36 \pm 0.01^{\mathrm{d}}$ \\
\hline Creatinine & $\begin{array}{c}147.3 \pm 9.01 \\
\mathrm{mmol} \cdot \mathrm{l}^{-1}\end{array}$ & $116.1 \pm 6.46^{\mathrm{a}}$ & $\begin{array}{c}234.5 \pm 13.4 \\
\mathrm{mg} \cdot \mathrm{g}^{-1} \text { of TP }\end{array}$ & $205.5 \pm 11.5$ \\
\hline Urea & $\begin{array}{c}7.11 \pm 0.24 \\
\mathrm{mmol} \cdot 1^{-1}\end{array}$ & $6.06 \pm 0.36^{\mathrm{b}}$ & $\begin{array}{c}6.04 \pm 0.25 \\
\mu \mathrm{mol} \cdot \mathrm{g}^{-1} \text { of TP }\end{array}$ & $5.69 \pm 0.37$ \\
\hline HS- & $\begin{array}{c}0.48 \pm 0.02 \\
\mathrm{U} \cdot \mathrm{ml}^{-1}\end{array}$ & $0.43 \pm 0.01^{\mathrm{c}}$ & $\begin{array}{c}6.76 \pm 0.32 \\
\mathrm{mU} \cdot \mathrm{mg}^{-1} \text { of } \mathrm{TP}\end{array}$ & $6.85 \pm 0.22$ \\
\hline SOD & $235 \pm 16.5$ & $201.3 \pm 13.74^{c}$ & $3305 \pm 271.3$ & $3237 \pm 213$ \\
\hline GSHPx & $\begin{array}{c}33.27 \pm 3.02 \\
\mathrm{mmol} \cdot \mathrm{l}^{-1}\end{array}$ & $26.66 \pm 2.38^{b}$ & $\begin{array}{r}486 \pm 37.6 \\
\mathrm{mg} \cdot \mathrm{g}^{-1} \text { of } \mathrm{TL}\end{array}$ & $381.5 \pm 36.3^{\mathrm{a}}$ \\
\hline Tot. cholesterol & $\begin{array}{c}2.12 \pm 0.07 \\
\mu \mathrm{mol} \cdot \cdot^{-1}\end{array}$ & $1.85 \pm 0.10^{\mathrm{b}}$ & $\begin{array}{c}236.6 \pm 17.9 \\
\mathrm{mmol} \cdot \mathrm{g}^{-1} \text { of TL }\end{array}$ & $266.2 \pm 17.5^{b}$ \\
\hline$\alpha$-Tocopherol & $3.89 \pm 0.59$ & $3.47 \pm 0.59$ & $0.39 \pm 0.08$ & $0.57 \pm 0.12$ \\
\hline Retinol & $\begin{array}{c}1.03 \pm 0.03 \\
\mathrm{mmol} \cdot \cdot^{-1}\end{array}$ & $1.02 \pm 0.03$ & $\begin{array}{c}0.08 \pm 0.02 \\
\mathrm{mmol} \cdot \mathrm{g}^{-1} \text { of } \mathrm{TL}\end{array}$ & $0.12 \pm 0.01^{\mathrm{c}}$ \\
\hline Triglycerides & $0.28 \pm 0.06$ & $0.23 \pm 0.03$ & $81.62 \pm 18.34$ & $88.27 \pm 13.58$ \\
\hline
\end{tabular}

Total lipids (TL), total protein (TP), malondialdehyde (MDA), sulphydryl groups (-SH), superoxide dismutase (SOD), glutathione peroxidase (GSHPx).

Results are presented as mean $\pm \operatorname{SEM}(\mathrm{n}=10) ;{ }^{\text {a }} P<0.01 ;{ }^{\mathrm{b}} P<0.05 ;{ }^{\mathrm{c}} P \leq 0.08 ;{ }^{\mathrm{d}} P \leq 0.18$

per $\mathrm{g}$ of TP. Sodium decrease is directly related to exercise-induced dehydration causing an increase of TP (Carlson 1987). Moreover, phosphorus increase (in $\mathrm{mg} \cdot \mathrm{g}^{-1}$ of TP) observed in our horses could be explained by its elevated requirement associated with the need of more energy for the working muscles (Pearson and Dijkman 1994). On the other hand, neither concentration of phosphorus and chlorine nor the amount of TP and ALB were affected by DJTR, and thus exercise-induced dehydration was not diagnosed in these horses. All results relating to DJTR are therefore presented in units per litre only. Studies where authors present biochemical indices in units per $\mathrm{g}$ of TP are limited; therefore, direct comparison of the results found after NPE in this manner is difficult.

\section{Enzymatic metabolism}

Our results indicate that the indices of enzymatic metabolism are dependent on the duration and type of exercise. In units per litre, a significant increase or tendency to increase was found in all enzymatic indices after NPE compared to $36 \mathrm{~h}$, what could diagnose some degree of muscle membrane leakage in these horses. Significant increase and subsequent decrease of CPK activity was found at the end and $16 \mathrm{~h}$ after the prolonged exercise in horses, according to Marlin et al. (2002). Based on the results expressed in units per $\mathrm{g}$ of TP, the NPE used in our experiment did not cause significant muscle damage. In light of the aforementioned findings, we can presume that the increased activities of enzymatic indices (in $\mathrm{U}^{-1} \mathrm{l}^{-1}$ or in $\mathrm{mU} \cdot \mathrm{mg}^{-1}$ of TP) after NPE may be attributable to different types of exercise to which the horses were not adapted by the regular jumping training. Nevertheless, our horses did not manifest any clinical signs of muscle fatigue, and all horses were able to accelerate to gallop in the final minute of exercise, which could indirectly indicate the presence of high energy phosphates in their skeletal muscles. We may thus speculate that 
NPE applied in our study depends primarily on the aerobic metabolism. Moreover, all these indices were significantly decreased at $36 \mathrm{~h}$ when the horses rested and had free access to water. On the other hand, unchanged activities of enzymatic indices but increased concentration of lactate after DJTR indicate that the horses were adapted to DJTR but this type of exercise triggered anaerobic metabolism pathways.

\section{Protein and lipid metabolism, and the antioxidant status}

Increased concentration of some indices of protein and lipid metabolism (in units per litre) found in our horses may indicate an elevation of the intermediary metabolism due to NPE. Furthermore, based on the significantly increased concentration of MDA and GSHPx activity expressed in units per litre as well as in units per $\mathrm{g}$ of TP. For this reason, we can presume that lipid peroxidation and oxidative stress occurred in these horses due to NPE. Williams et al. (2004) found that GSHPx activity in $\mathrm{mU} / \mathrm{mg}$ of TP was significantly increased $(P<0.05)$ but no change was found in the concentration of $\alpha$-tocopherol, which was adjusted to albumin due to changes in body fluid redistribution during endurance exercise. Similarly to our findings, when expressed as units per g of TP, Balogh et al. (2001) found unchanged activity of GSHPx and SOD (both in U/g of TP), and unaffected index of lipid peroxidation (in $\mathrm{mmol} / \mathrm{g}$ of TP) in pentathlon competition finishing horses, but the index of lipid peroxidation was decreased after $24 \mathrm{~h}$ of rest.

We can conclude that NPE applied in our study induced changes in some biochemical indices that are indicative of muscle membrane leakage, oxidative stress, and mineral, protein and lipid metabolism alterations. Moreover, the blood indices counted in units per $\mathrm{g}$ of TP may reflect biochemical changes caused by NPE more accurately because this calculation should diminish the impact of prolonged exercise-induced dehydration on the misinterpretation of these findings. These results also demonstrated that trained horses adapted to regular jumping exercise are exposed to oxidative and metabolic stress by NPE. All biochemical changes in response to NPE were compensated during the following 36 $\mathrm{h}$ when the horses rested and had free access to water, but further research is required to establish the optimal recovery time.

\section{Acknowledgement}

This work was supported by the Grant Agency for Science, VEGA of the Slovak Republic, Grant No 1/0614/09 and No 1/0498/12, and by the Science and Technology Assistance Agency of the Slovak Republic, Grant No APVT-51-004804.

\section{References}

Balogh N, Gaal T, Ribiczeyne PS, Petri A 2001: Biochemical and antioxidant changes in plasma and erythrocytes of pentathlon horses before and after exercise. Vet Clin Pathol 30: 214-218

Bax D, Peters FF, Vannoort JPM, Agterdenbos J 1986: The determination of selenium with hydride generation AAS. 2. The role of sodium-borohydride and hydrogen gas. Spectrochim Acta B Atomic Spectrosc 41: 275-282

Bezdekova B, Jahn P, Vyskocil M, Plachy J 2005: Gastric ulceration and exercise intensity in standardbred racehorses in Czech Republic. Acta Vet Brno 74: 67-71

Carlson GP 1987: Hematology and body fluids in equine athlete. In: Gillespie JR, Robinson NE, Davis (Eds.): Equine exercise physiology, ICEEP Publication, CA, pp. 393-425

Ellman GL 1958: Tissue sulfhydryl groups. Arch Biochem Biophysiol 82: 70-77

Flaminio MJBF, Bonnie RR 1998: Fluid and electrolyte balance in endurance horses. Vet Clin North Am Equine Pract 14: 147-158

Jo C, Ahn DU 1998: Fluorometric analysis of 2-thiobarbituric acid reactive substances in Turkey. Poult Sci 77: 475-480

Marlin DJ, Fenn K, Smith N, Deaton CD, Roberts CA, Harris PA, Dunster C, Kelly FJ 2002: Changes in circulatory antioxidant status in horses during prolonged exercise. J Nutr 132: 1622S-1627S

McKeever KH, Hinchcliff KW, Reed SM, Robertson JT 1993: Role of decreased plasma volume in hematocrit alterations during incremental treadmill exercise in horses. Am J Physiol 265: 404-408 
Pearson RA, Dijkman JT 1994: Nutritional impications of work in draught animals. Procc Nutr Soc 50: 169-179

Robert C, Goachet AG, Fraipont A, Votion DM, van Erck E, Leclerc JL 2010: Hydration and electrolyte balance in horses during an endurance season. Equine Vet J 42: 98-104

Rose RJ, Hodgson DR 1994: Hematology and biochemistry. In: Hodgson DR, Rose RJ (Eds.): The athletic horse. Principles and practice of equine sport medicine, Saunders, USA, pp. 63-78

Snow DH, Kerr MG, Nimmo MA, Abbott EM 1982: Alterations in blood, sweat, urine and muscle composition during prolonged exercise in the horse. Vet Rec 110: 377-384

Tuckova M, Kastel R 1999: The methodology for the simultaneous analysis of vitamins A, E, and beta-carotene in animal blood plasma by gradient and isocratic methods of HLPC. Folia Vet 43: 85-91

Williams CA, Kronfeldt DS, Hess TM, Saker KE, Waldron JN, Crandell KM, Hoffman RM, Harris PA 2004: Antioxidant supplementation and subsequent oxidative stress of horses during an $80-\mathrm{km}$ endurance race. J Anim Sci 82: 588-594

Zobba R, Ardu M, Niccolini S, Cubeddu F, Dimauro C, Bonelli P, Dedola C, Visco S, Parpaglia MLP 2011: Physical, hematological, and biochemical responses to acute intense exercise in Polo horses. J Equine Vet Sci 31: $542-548$ 